\title{
Manifestation of remote response over the equatorial Pacific in a climate model
}

\author{
Vasubandhu Misra ${ }^{1}$ and L. Marx ${ }^{1}$ \\ Received 28 February 2007; revised 31 May 2007; accepted 27 June 2007; published 19 October 2007.
}

[1] In this paper we examine the simulations over the tropical Pacific Ocean from longterm simulations of two different versions of the Center for Ocean-Land-Atmosphere Studies (COLA) coupled climate model that have a different global distribution of the inversion clouds. We find that subtle changes made to the numerics of an empirical parameterization of the inversion clouds can result in a significant change in the coupled climate of the equatorial Pacific Ocean. In one coupled simulation of this study we enforce a simple linear spatial filtering of the diagnostic inversion clouds to ameliorate its spatial incoherency (as a result of the Gibbs effect) while in the other we conduct no such filtering. It is found from the comparison of these two simulations that changing the distribution of the shallow inversion clouds prevalent in the subsidence region of the subtropical high over the eastern oceans in this manner has a direct bearing on the surface wind stress through surface pressure modifications. The SST in the warm pool region responds to this modulation of the wind stress, thus affecting the convective activity over the warm pool region and also the large-scale Walker and Hadley circulation. The interannual variability of SST in the eastern equatorial Pacific Ocean is also modulated by this change to the inversion clouds. Consequently, this sensitivity has a bearing on the midlatitude height response. The same set of two experiments were conducted with the respective versions of the atmosphere general circulation model uncoupled to the ocean general circulation model but forced with observed SST to demonstrate that this sensitivity of the mean climate of the equatorial Pacific Ocean is unique to the coupled climate model where atmosphere, ocean and land interact. Therefore a strong case is made for adopting coupled ocean-land-atmosphere framework to develop climate models as against the usual practice of developing component models independent of each other.

Citation: Misra, V., and L. Marx (2007), Manifestation of remote response over the equatorial Pacific in a climate model, J. Geophys. Res., 112, D20105, doi:10.1029/2007JD008597.

\section{Introduction}

[2] The coupled climate over the tropical Pacific Ocean has received a lot of attention primarily because El Niño and the Southern Oscillation (ENSO), the largest observed variability at interannual scales, occurs over this region. Furthermore, the colocation of the rising branch of the Walker circulation, and strong atmospheric heating from deep convection over this warm pool region that drives the global climate including ENSO and the Asian-Australian monsoon [Webster, 1994; Webster et al., 1998] also adds impetus to understand the dynamics and physics of the climate over this part of tropical Pacific Ocean. The earliest review of coupled simulations over equatorial Pacific Ocean [McCreary and Anderson, 1991; Neelin et al., 1992; Mechoso et al., 1995] to more recent coupled modeling

\footnotetext{
${ }^{1}$ Center for Ocean-Land-Atmosphere Studies, Institute of Global Environment and Society, Inc., Calverton, Maryland, USA.

Copyright 2007 by the American Geophysical Union. 0148-0227/07/2007JD008597\$09.00
}

studies [Rao and Sperber, 2002; Schneider, 2002] indicate, the perpetuity of cold bias in coupled climate models across the equatorial Pacific, albeit with varying magnitudes. There has been a considerable amount of work conducted to understand the cause of this error [Stockdale et al., 1994; Ma et al., 1994; Yu and Mechoso, 1999a, 1999b; Gordon et al., 2000]. Most of these studies isolated physical processes that were specific to their models. However, a growing perception in the community is that poor representation of the marine boundary layer clouds (also referred as stratus clouds or inversion clouds) may have an important bearing on the mean climate and its variability over the equatorial Pacific Ocean [Bretherton et al., 2004; Gordon et al., 2000]. Despite the observed propensity of these inversion clouds to cover vast stretches of the tropical and subtropical oceans, it has proven rather difficult for climate models to simulate them [Bretherton et al., 2004]. This deficiency in climate models stems from the shallow nature of these clouds (typically a few hundred meters thick) and the complex physical processes that maintain them [Wang et al., 2004].

[3] This study investigates the role of the inversion clouds on the mean coupled climate of the equatorial Pacific 
Table 1. Outline of the COLA AGCM V3.2 Used in This Study

\begin{tabular}{|c|c|}
\hline Process & $\mathrm{V} 3.2$ \\
\hline $\begin{array}{l}\text { Advection } \\
\text { Deep convection }\end{array}$ & $\begin{array}{l}\text { dynamical core [Kiehl et al., 1998]; } \\
\text { dependent variables are spectrally } \\
\text { treated except for moisture } \\
\text { which is advected by semi-Lagrangian } \\
\text { scheme relaxed Arakawa Schubert } \\
\text { scheme [Bacmeister et al., 2000] }\end{array}$ \\
\hline Longwave radiation & Collins et al. [2002] \\
\hline Boundary layer & nonlocal [Hong and Pan, 1996] \\
\hline Land surface process & $\begin{array}{l}\text { Xue et al. [1991, 1996], } \\
\text { Dirmeyer and Zeng [1999] }\end{array}$ \\
\hline Shallow convection & Tiedtke [1984] \\
\hline Shortwave radiation & Briegleb [1992] \\
\hline $\begin{array}{l}\text { Diagnostic cloud fraction } \\
\text { optical properties }\end{array}$ & Kiehl et al. [1998] \\
\hline
\end{tabular}

Ocean and its variability. Observational studies indicate that these clouds cover nearly $34 \%$ of the ocean surface [Klien and Hartmann, 1993], thereby significantly contributing to the global albedo [Hartmann et al., 1992]. Additionally, these clouds lead to reduced absorbed solar radiation at the top of the atmosphere and at its interface with the ocean at the bottom, cooling the underlying atmosphere and ocean [Randall et al., 1984]. Furthermore, some coupled modeling studies suggest that these inversion clouds play an important role in maintaining the asymmetric time mean state and the annual cycle of the eastern Pacific Ocean [Philander et al., 1996; Yu and Mechoso, 1999a; Ma et al., 1996; Gordon et al., 2000]. The important role of these clouds in regulating the global climate and its rather poor representation in numerical models is also reflected in part by some of the more recent extensive field experiments conducted over the region such as the Pan American Climate Studies Tropical Eastern Pacific Study (PACS TEPPS [Yuter et al., 2000]) the Dynamics and Chemistry of Marine Stratocumulus (DYCOMS [Stevens et al., 2003]), and the East Pacific Investigation of Climate (EPIC [Bretherton et al., 2004]).

[4] An idealized coupled modeling study was conducted by Ma et al. [1996] to understand the effectiveness of stratus clouds off the Peruvian coast on equatorial Pacific climate. In that study, stratus clouds were artificially altered to provide a persistent and high coverage off the Peruvian coast only. They showed that a significant cooling of SST occurs under the prescribed stratus deck besides remote ocean cooling from modulation of the wind stress and associated wind driven evaporation. In a similar study, Gordon et al. [2000] reconfirmed these results with another coupled model. Furthermore they showed that with more realistic inversion clouds certain features of the interannual variability over the eastern Pacific Ocean also improve. This present study differs from some of the earlier studies in the fact that the stratus clouds are not prescribed in any of the model simulations conducted in this work. Furthermore this study promotes the idea of the development of coupled models in a coupled framework in lieu of developing the component models of atmosphere, ocean and land independent of each other by showing the remote response of the equatorial Pacific ocean to these inversion clouds.

[5] In the following section we briefly describe the models followed by a description of the design of experi- ments. In section 4 we explain the results followed by a discussion with concluding remarks in section 5 .

\section{Model Description}

[6] The model used in this study is the Center for OceanLand-Atmosphere Studies (COLA) coupled model that comprises the modular ocean model version 3.0 (MOM3 [Pacanowski and Griffies, 1998]) and a recently developed atmospheric general circulation model (AGCM V3.2 [Misra et al., 2007]). The coupled model is described in greater detail by Misra et al. [2007]. A brief outline of the AGCM is provided in Table 1. The details of the parameterization of the inversion clouds central to this study is provided in the following section. The AGCM with a horizontal resolution of T62 spectral truncation ( $\approx 212 \mathrm{~km}$ grid resolution) is coupled to MOM3 with a coupling interval of one day. MOM3 has a uniform zonal resolution of $1.5^{\circ}$ while the meridional resolution is $0.5^{\circ}$ between $10^{\circ} \mathrm{S}$ and $10^{\circ} \mathrm{N}$, gradually increasing to $1.5^{\circ}$ at $30^{\circ} \mathrm{N}$ and $30^{\circ} \mathrm{S}$ and fixed at $1.5^{\circ}$ in the extratropics.

\section{Design of Experiments}

[7] Two coupled simulations are conducted over a 70-year period, each with slightly different parameterization of the inversion clouds. Fundamentally, the parameterization of the inversion clouds follows from Kiehl et al. [1998]. The fraction of inversion clouds $\left(C_{i n v}\right)$ is determined from:

$$
C_{i n v}=-6.67\left[\left(\frac{\partial \theta}{\partial p}\right)-\left(\frac{\partial \theta}{\partial p}\right)_{c}\right] \times R H f,
$$

where $\left(-\frac{\partial \theta}{\partial p}\right)_{c}$ is the critical lapse rate that must be exceeded for inversion clouds to be diagnosed (in our case it is $4 \times$ $10^{-2} \mathrm{deg} / \mathrm{hPa}$ ). RHf is a function of the relative humidity given by

$$
\begin{gathered}
0.0 \text { if } \mathrm{RH}<0.6 \\
1.0-\frac{(0.8-R H)}{0.2} \text { if } 0.6 \leq \mathrm{RH} \leq 0.8 \\
1.0 \text { if } 0.8<\mathrm{RH} .
\end{gathered}
$$

[8] In addition, the inversion clouds are not invoked at a grid point if convection was active at the same given time step. The inversion clouds are then used to diagnose the total cloud fraction using maximum overlap between clouds. Generally, this algorithm produces inversion clouds in $900-700 \mathrm{hPa}$ layer in the vertical over subtropical and nonconvective regions of the tropics including the equatorial cold tongue over the eastern Pacific Ocean. In the control coupled simulation of this study the fraction of inversion cloud diagnosed from the above methodology are smoothed using a one-dimensional three-point filter $\left(\mathrm{C}_{i n v}^{f}\right)$ :

$$
C_{i n v}^{f}=\left[0.25 C_{i n v}^{i+1}+0.5 C_{i n v}^{i}+0.25 C_{i n v}^{i-1}\right],
$$




\section{Control}

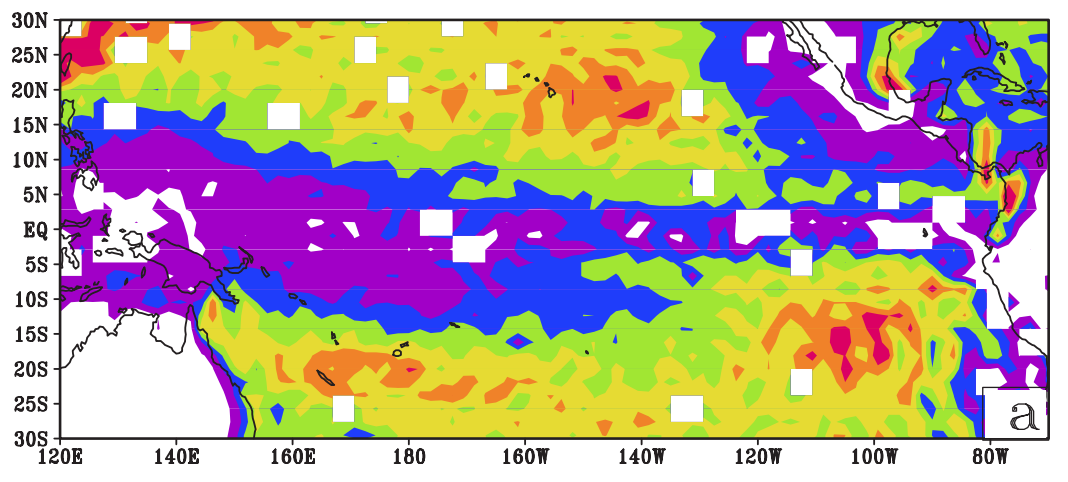

ISCCP

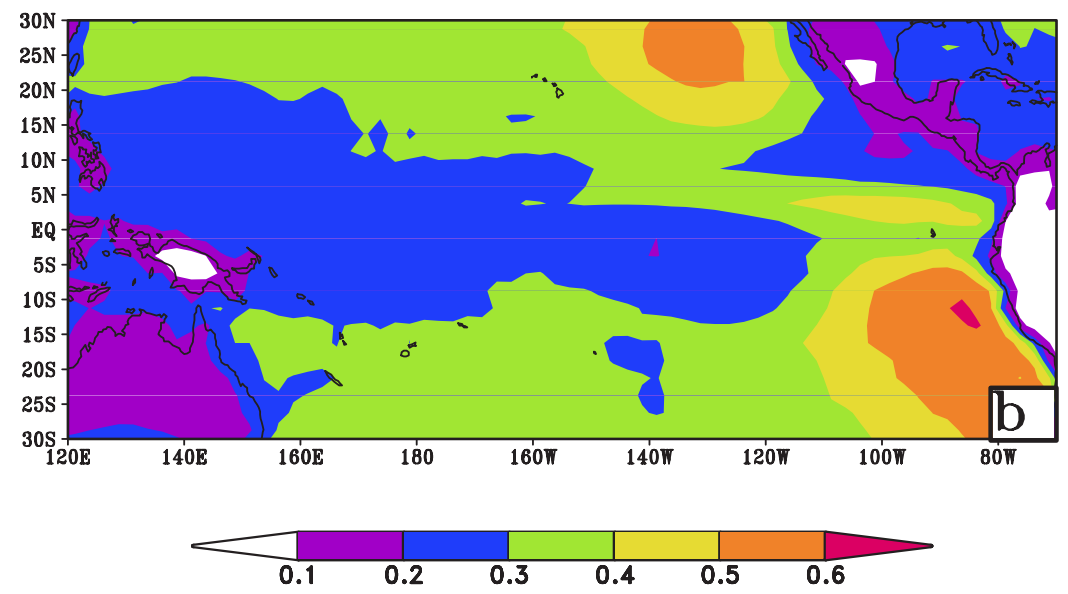

Figure 1. Climatological annual mean low-level cloud fraction from (a) control and (b) observations of the International Satellite Cloud Climatology Project [Rossow and Schiffer, 1999].

where i refers to any given grid point of the AGCM. In the Expt coupled simulation no such filtering of the inversion clouds is adopted.

[9] The filter is used in the control to reduce the spectral effects on the inversion clouds generated by the Gibbs phenomenon in the prognostic fields of the AGCM. It should be noted that the contribution to the low-level clouds in the control comes from the inversion clouds described above and relative humidity based clouds [Slingo, 1987; Kiehl et al., 1998]. Furthermore, the low-level clouds in the control are diagnosed if the cloud top pressure is below $680 \mathrm{hPa}$. The smoothing was done only in the longitudinal direction because of practical constraints in coding filters that involved smoothing across latitudes. The COLA AGCMV3.2 (similar to other AGCMs) is coded to run in distributed memory systems using Message Passing Interface (MPI) that decomposes latitude groups of the global array of discrete grid points of longitudes and height. Therefore computations across latitudes in the physics of the AGCM is cumbersome and rather impractical. Furthermore, we found that by filtering only in the longitudinal direction, the apparent noise observed in the downwelling shortwave flux is considerably reduced compared to Expt in which no filter was applied to the inversion clouds.

[10] It should be noted that the spectral effects on clouds are more apparent in the current version of the COLA AGCM than in the earlier versions of the COLA AGCM [Schneider, 2002] primarily because the fourth-order horizontal diffusion coefficient has been reduced from $2.5 \times 10^{16} \mathrm{~s}^{-4}$ to $1 \times 10^{14} \mathrm{~s}^{-1}$, a change of two orders of magnitude. Furthermore, the orography was changed to that in NCEP reanalysis model [Kalnay et al., 1996], which has sharper gradients than that used in the earlier version of the COLA AGCM [Fennessy et al., 1994].

[11] The ocean model was integrated from the initial state of rest with initial conditions of temperature and salinity of Levitus [1982], and forced with climatological wind stress derived from the special sensor microwave imager (SSMI) for a period of 100 years. Thereafter, each of the coupled simulations was integrated for a period of 70 years. The results in this study are analyzed from the last 45 years of the integration, discarding the first 25 years as a spin-up period of the coupled model.

[12] In Figures 1a and 1b we show the climatological annual mean low-level winds in the control run and in 
observations (International Satellite Cloud Climatology Project [Rossow and Schiffer, 1999]). The fraction of the low-level clouds in Figure 1a from the control run is a reasonable rendition of the observations (Figure 1b). However, the control simulation produces erroneously excessive lowlevel clouds off the equator in either hemisphere in the western Pacific. In addition the low-level clouds are slightly deficient in the warm pool region of the western Pacific Ocean.

[13] In Figures $2 \mathrm{a}$ and $2 \mathrm{~b}$ we show the climatological mean inversion cloud fraction integrated from the surface to the top of the atmosphere from the control and Expt coupled simulations overlaid with contours of climatological height of $1000 \mathrm{hPa}$ respectively. It may be noted that the shading interval in Figure 2 differs from that in Figure 1. The inversion clouds are most prominent in the equatorial cold tongue of the eastern Pacific Ocean and in the trade wind inversion region in the southeastern (northeastern) flank of the northern (southern) subtropical highs. The cloud fraction (Figure 2b) is far noisier apparent from the strong zonal gradients of the inversion cloud. The difference of the cloud fraction between the two coupled experiments shown in Figure 2c further corroborates this.

[14] In comparing Figures $1 \mathrm{a}$ and $2 \mathrm{a}$, the model feature of relatively low fraction of inversion clouds in comparison to the total amount of low level clouds in the control become apparent. This is primarily because the inversion in the control model is very weak. This model error is also present in other contemporary coupled climate models [Hu et al., 2007]. However, the optical properties of the clouds are determined empirically on the basis of the temperature and pressure [Kiehl et al., 1998] and is insensitive to how clouds are diagnosed.

[15] Additionally, two more experiments were conducted with the AGCMs of the control and Expt coupled models forced with observed SST from Hadley center sea ice and sea surface temperature data set (HADISST [Rayner et al., 2003]) for a period of 45 years from 1901 to 1945. These AGCM experiments were conducted to understand if air-sea coupling is necessary to understand the sensitivity of the tropical Pacific climate to the inversion clouds. A summary of all the model integrations is provided in Table 2.

\section{Results}

[16] The mean state of the simulations used in the analysis of the model results in this study are derived from the last 45 years of the coupled model integration that includes all calendar months. The model results from the control simulation of this study has been extensively validated with observations by Misra et al. [2007]. In the following subsections we will highlight the differences between the simulations in some of the variables that were found to be critical to explain the sensitivity of the mean climate over the equatorial Pacific to the inversion clouds.

\subsection{Net Heat Flux}

[17] In Figure 3 we show the climatological net downward surface heat flux from the control run followed by its difference with the Expt. In Figure 3a the cold tongue in the eastern equatorial Pacific bereft of deep convection, is quite apparent with over $250 \mathrm{~W} \mathrm{~m}^{-2}$ heat flux straddled by region of lower net heat flux in both hemispheres. As shown in
Figure $3 \mathrm{~b}$ the three point smoothing of inversion clouds in the control simulation results in over $15 \mathrm{~W} \mathrm{~m}^{-2}$ more net heat flux relative to the Expt in the warm pool region. These differences in the net heat flux between the coupled simulations over the warm pool region can largely be explained from the differences in the climatological downwelling shortwave flux shown in Figure 4. In Figure 4a we see that near convective cloud free regions of equatorial eastern Pacific and subtropical oceans receive more downwelling shortwave flux than over the deep convective regions of the warm pool, south pacific convergence zone and the intertropical convergence zone over the Pacific Ocean around $5^{\circ} \mathrm{N}$.

[18] More importantly, the differences between the simulations shown in Figure $4 \mathrm{~b}$ is similar in magnitude and spatial extent to the corresponding differences in the net heat flux shown in Figure $3 \mathrm{~b}$ over the warm pool region. The inversion clouds are nearly nonexistent in the warm pool region (or relatively far less than in the subtropical oceans and in the equatorial cold tongue region) and yet their impact on the radiative fluxes (as diagnosed from Figures $3 \mathrm{~b}$ and $4 \mathrm{~b}$ ) are abundantly clear over the warm pool region. This suggests the presence of some remote dynamical response.

[19] In contrast, over the subtropical region poleward of $10^{\circ}$ latitude in both hemispheres the differences especially between the control and Expt in downwelling shortwave flux are generally not of the same sign as the difference in the net heat flux (Figure 3b). This suggests that over this region the fluxes of latent heat, longwave and sensible heat are compensating for the change in the downwelling shortwave flux. This is an important point of difference from the warm pool region. Therefore a direct consequence of the more coherent inversion clouds in the control coupled model is, it cuts off more downwelling shortwave flux at the surface over the subtropical Pacific Oceans (poleward of $10^{\circ}$ in either hemispheres) than in the Expt.

\subsection{Sea Surface Temperature}

[20] In Figures 5a and 5b we show the climatological annual mean SST from the control simulation and its error, respectively. The climatological annual mean error in SST is computed from a 45 year mean of the HADISST computed over the time period of 1901 to 1945. Apart from the warm bias in the eastern Pacific boundary, which is strongly related to lack of adequate stratus clouds of the control simulation, there is significant cold bias in the equatorial central and western Pacific Ocean (Figure 5a). This cold bias in the equatorial Pacific Ocean is larger in the control simulation compared to the Expt (Figure 5c). These differences between the simulations cannot be obviously explained from the differences observed earlier in the net heat flux and in the downwelling shortwave flux. The surplus of net heat flux in the control simulation compared to the Expt would warrant warmer SST if all other terms in its heat budget were negligible. It should be mentioned that the relatively colder bias in the control compared to the Expt is consistent with a similar result of Gordon et al. [2000]. In their study the coupled simulation with the prescribed (more realistic observed) low-level clouds increased the cold tongue bias over the equatorial Pacific Ocean. 


\section{Control: Inversion clouds}
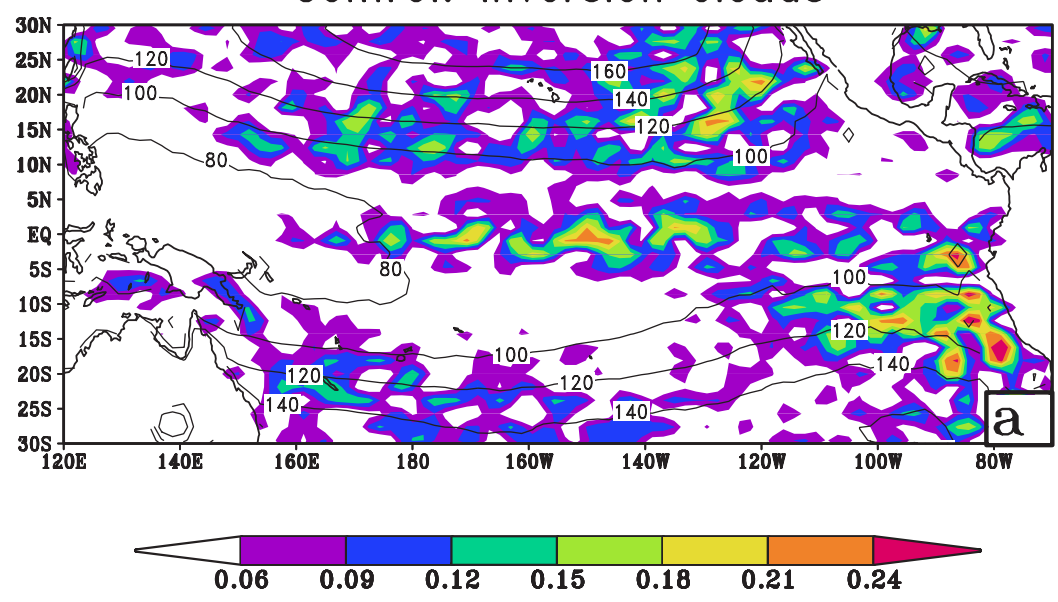

\section{Expt: Inversion clouds}

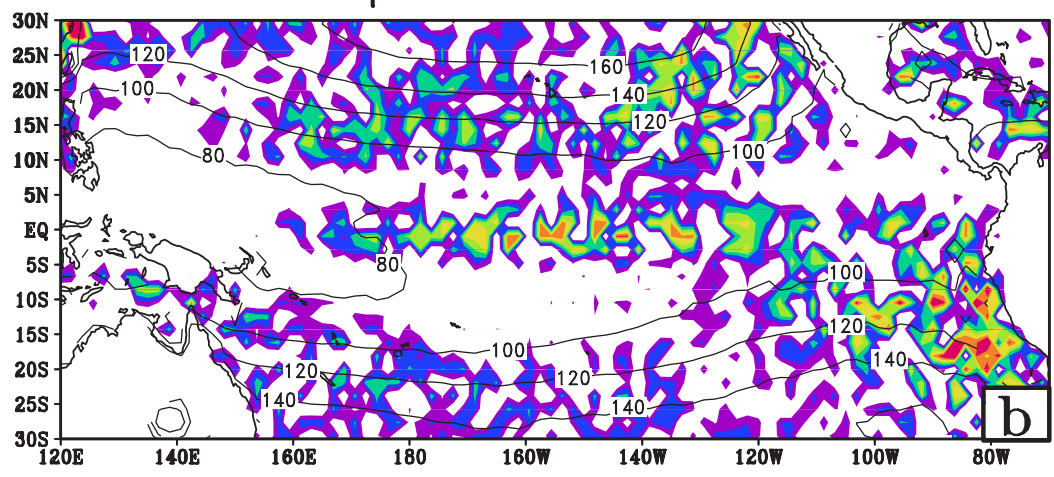

Control-Expt: Inversion clouds
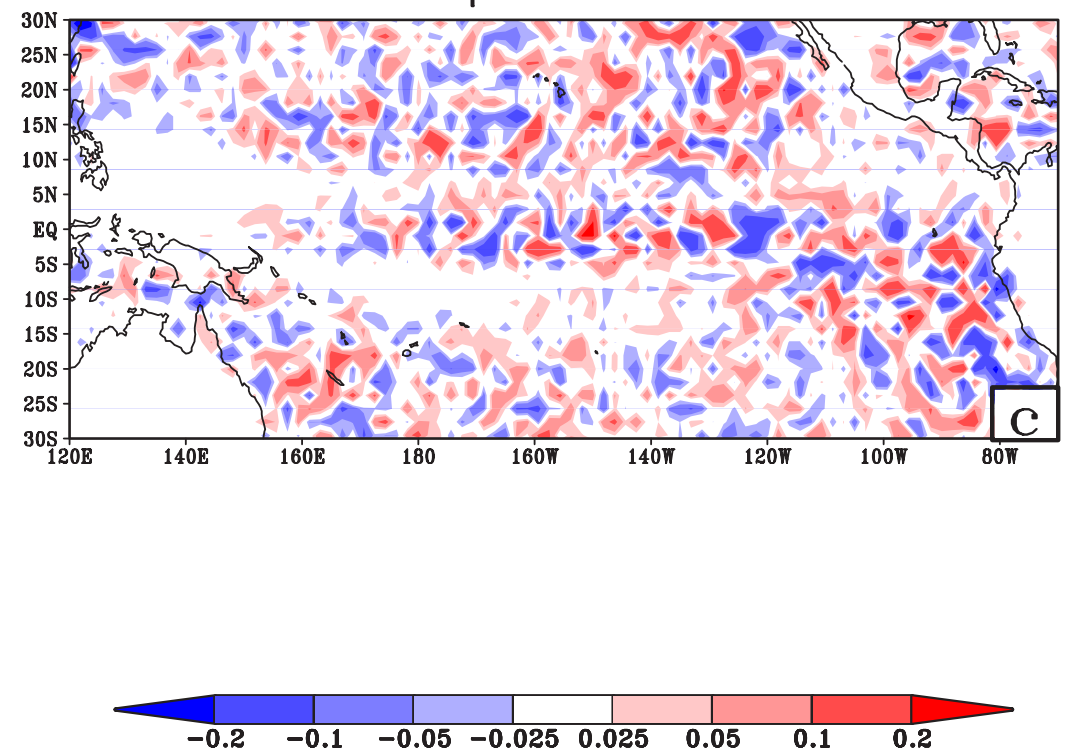

Figure 2. Climatological annual mean inversion cloud fraction vertically integrated from the model surface to the top of the atmosphere in (a) control and (b) Expt and (c) their difference. The contours of the climatological $1000 \mathrm{hPa}$ heights (in meters) from the corresponding simulations are also overlaid. 
Table 2. Summary of the Model Integrations Conducted in This Study

\begin{tabular}{|c|c|}
\hline Experiment Name & Brief Description \\
\hline Control & $\begin{array}{l}\text { coupled COLA model with } 3 \text { point } \\
\text { smoothing of the inversion clouds }\end{array}$ \\
\hline Expt & $\begin{array}{l}\text { coupled COLA model without any } \\
\text { smoothing of the inversion clouds }\end{array}$ \\
\hline $\operatorname{AGCM}(\mathrm{C})$ & $\begin{array}{l}\text { forced integration of the AGCM } \\
\text { component of the control coupled } \\
\text { model with observed SST }\end{array}$ \\
\hline AGCM(E) & $\begin{array}{l}\text { forced integration of the AGCM } \\
\text { component of the Expt coupled } \\
\text { model with observed SST }\end{array}$ \\
\hline
\end{tabular}

\subsection{Wind Stress}

[21] In Figures $6 \mathrm{a}$ and $6 \mathrm{~b}$ we show the wind stress from the control simulation and its difference with the Expt respectively. In Figure 6b, the control simulation displays a stronger equatorial easterlies west of the dateline relative to the Expt, where the SST differences (Figure 5c) were found to be the largest. This relative increase in the equatorial easterly wind stress in the control simulation is a result of the increase in equatorial surface pressure gradient compared to the Expt. In Figure 7a, the climatological surface pressure from the control simulation is plotted after removing its zonal mean. The contours of the climatological $1000 \mathrm{hPa}$ heights from the control simulation is also overlaid to show the location of the subtropical highs. The corresponding difference of surface pressure from the Expt simulation is plotted in Figure $7 \mathrm{~b}$. It is apparent from Figure $7 \mathrm{~b}$ that the surface pressure in the eastern and the central (western) Pacific Ocean is higher (lower) in the control relative to the Expt (Figure 7b). This sets up a stronger surface pressure gradient that is conducive for stronger easterlies in the control simulation compared to the Expt shown earlier in Figure 6.

\subsection{Large-Scale Circulation}

[22] As a consequence of the surface easterlies becoming stronger in the control relative to the Expt, the east-west Walker circulation also strengthens. This is illustrated in
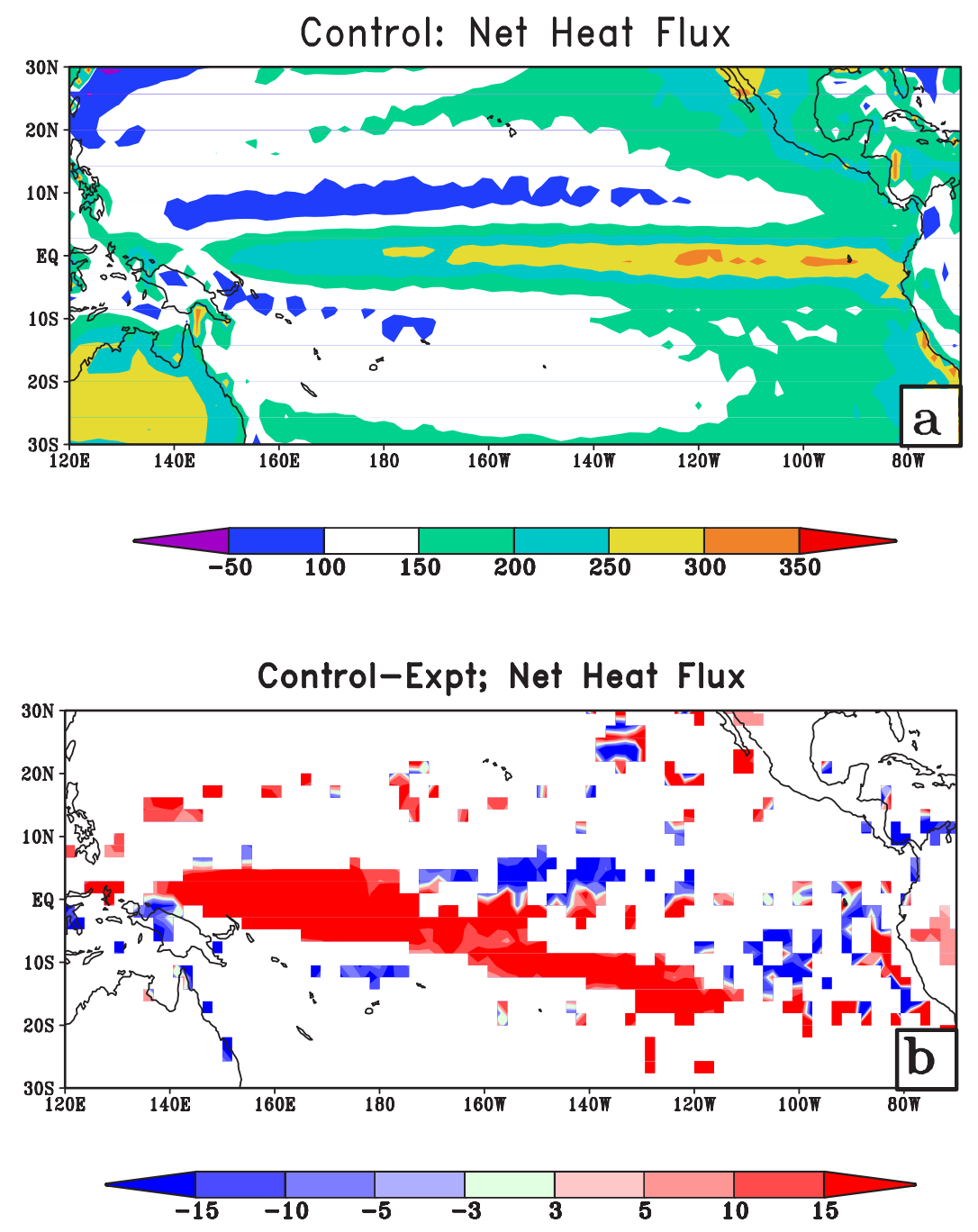

Figure 3. (a) Climatological annual mean net heat flux from the control simulation and (b) its difference with the corresponding annual mean from Expt (only significant values at 10\% significance level according to t-test are shaded). Units are $\mathrm{W} \mathrm{m}^{-2}$. 


\section{Control: Downwelling Shortwave Flux at Surface}

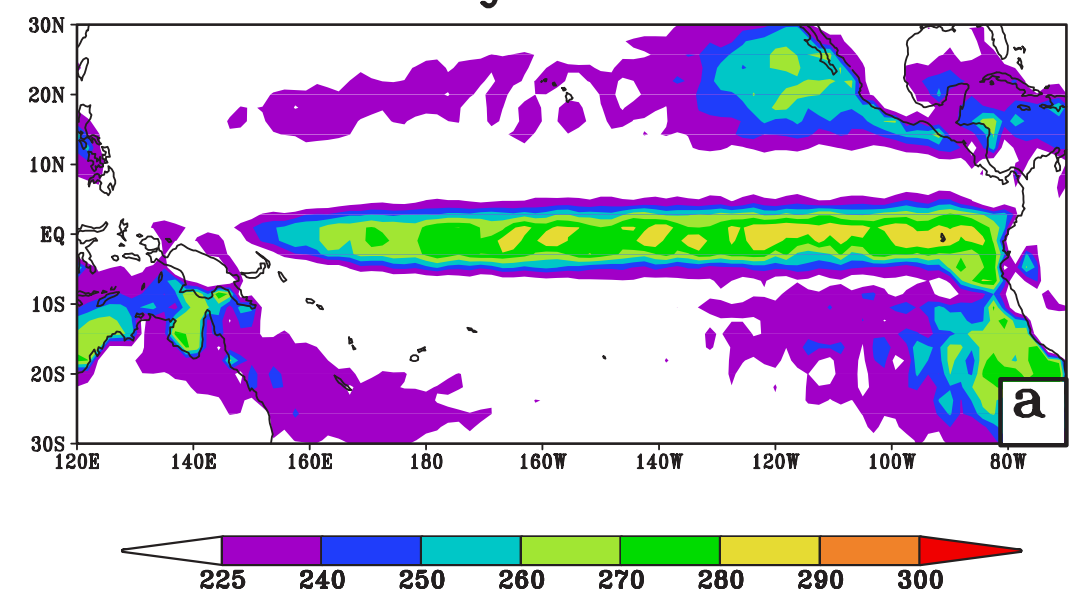

Control-Expt; Downwelling Shortwave Flux at Surface

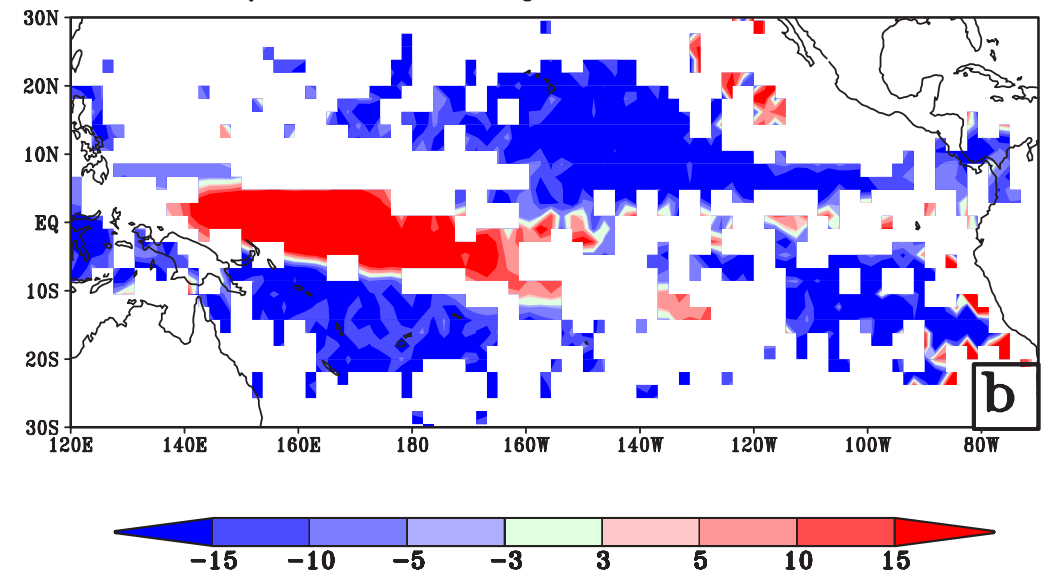

Figure 4. Same as Figure 3 but for downwelling shortwave flux at surface.

Figures $8 \mathrm{a}$ and $8 \mathrm{~b}$ which shows the climatological velocity potential and divergent wind from the control and its difference with the Expt simulation at $200 \mathrm{hPa}$ respectively. The ascending cell of the Walker circulation in the control has shifted further westward over the tropical Indian Ocean relative to the Expt (Figure 8b). The stronger easterlies in the control enhances the surface evaporation and fuels downstream deep convection over equatorial Indian Ocean relative to the experiment. This is corroborated further in Figures $9 \mathrm{a}$ and $9 \mathrm{~b}$ which show the fresh water flux (P-E) in the control and its difference with the Expt respectively. The control shows a significantly larger fresh water flux into the equatorial Indian Ocean suggesting stronger convective activity relative to the Expt. In fact this difference in fresh water flux over the tropical Pacific Ocean strongly resembles the net heat flux difference seen earlier in Figure 3b but with signs reversed. It is also seen in Figure 8 that the local Hadley type circulation over the Indian Ocean is more vigorous in the control relative to the Expt.

\subsection{Role of Air-Sea Coupling}

[23] Is this sensitivity of the equatorial Pacific annual mean climate to inversion clouds unique to the coupled ocean-atmosphere framework? To answer this question we compare and contrast here the differences between $\operatorname{AGCM}(\mathrm{C})$ and $\operatorname{AGCM}(\mathrm{E})$ with the differences between the coupled integrations. In Figures $10 \mathrm{a}$ and $10 \mathrm{~b}$ we show the difference of the net heat flux and the downwelling shortwave flux between $\operatorname{AGCM}(\mathrm{C})$ and $\operatorname{AGCM}(\mathrm{E})$. Unlike the difference between the coupled simulations (Figures $3 \mathrm{~b}$ and $4 \mathrm{~b}$ ) there is no significant difference of the fluxes over the warm pool region. Furthermore the differences of the downwelling shortwave flux over the subtropical Pacific Ocean between the uncoupled simulations in Figure 10b is far less than the differences between the coupled simulations in Figure 4b. Again, most of the differences in the net heat flux (Figure 10a) can be explained by the differences in the downwelling shortwave flux. Likewise, there is no significant difference in the surface easterlies and zonal surface pressure gradients over warm pool region between $\operatorname{AGCM}(\mathrm{C})$ and $\operatorname{AGCM}(\mathrm{E})$ (not shown). This is further corroborated by the insignificant differences in the fresh water flux between $\operatorname{AGCM}(C)$ and $\operatorname{AGCM}(E)$ shown in Figure 11 relative to that shown in Figure $7 \mathrm{~b}$ for the coupled simulations. These results clearly confirm that the modulation of the SST gradients in the equatorial Pacific Ocean through changes in wind stress and surface heat flux can cause remote responses over western equatorial Pacific 

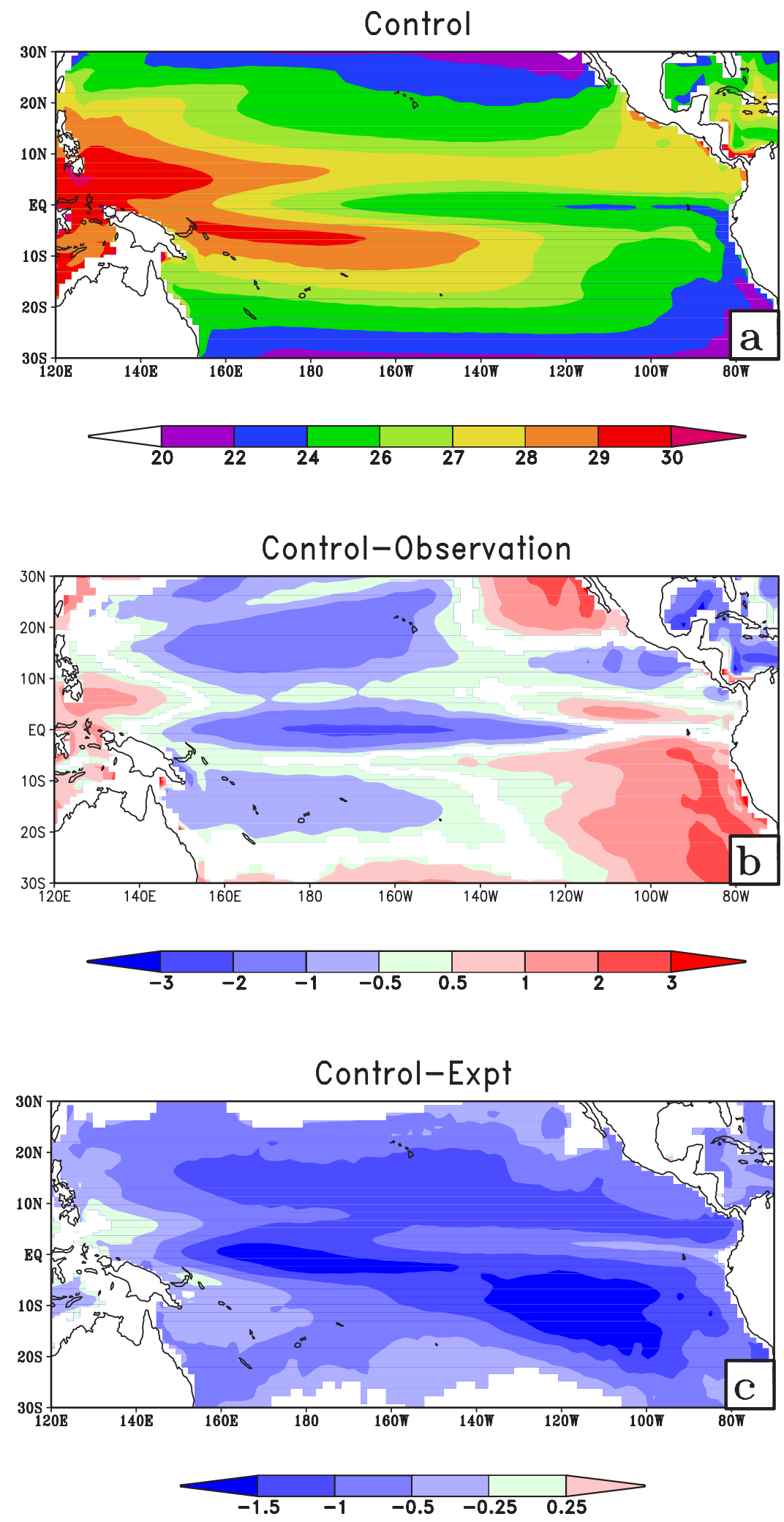

Figure 5. Climatological annual mean (a) SST from the control simulation, (b) systematic error of SST in the control simulation and (c) difference in SST between the control and the EXPT simulations. In Figures $5 \mathrm{~b}$ and $5 \mathrm{c}$ only significant values at $10 \%$ significance level according to t-test are shaded. 

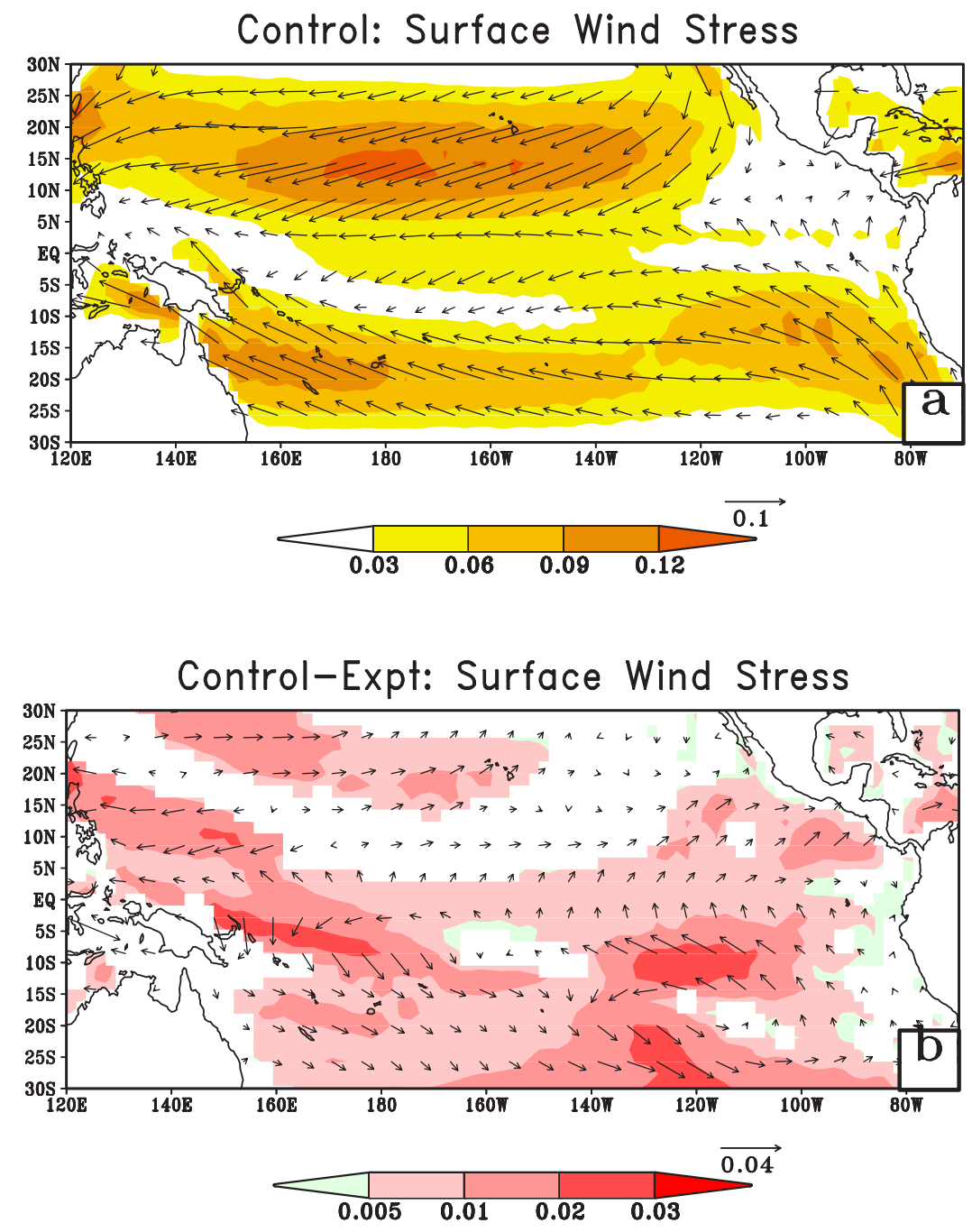

Figure 6. Same as Figure 3 but for surface wind stress. Color shading denotes the magnitude of the wind stress. Units are $\mathrm{Nm}^{-2}$. 


\section{Control}
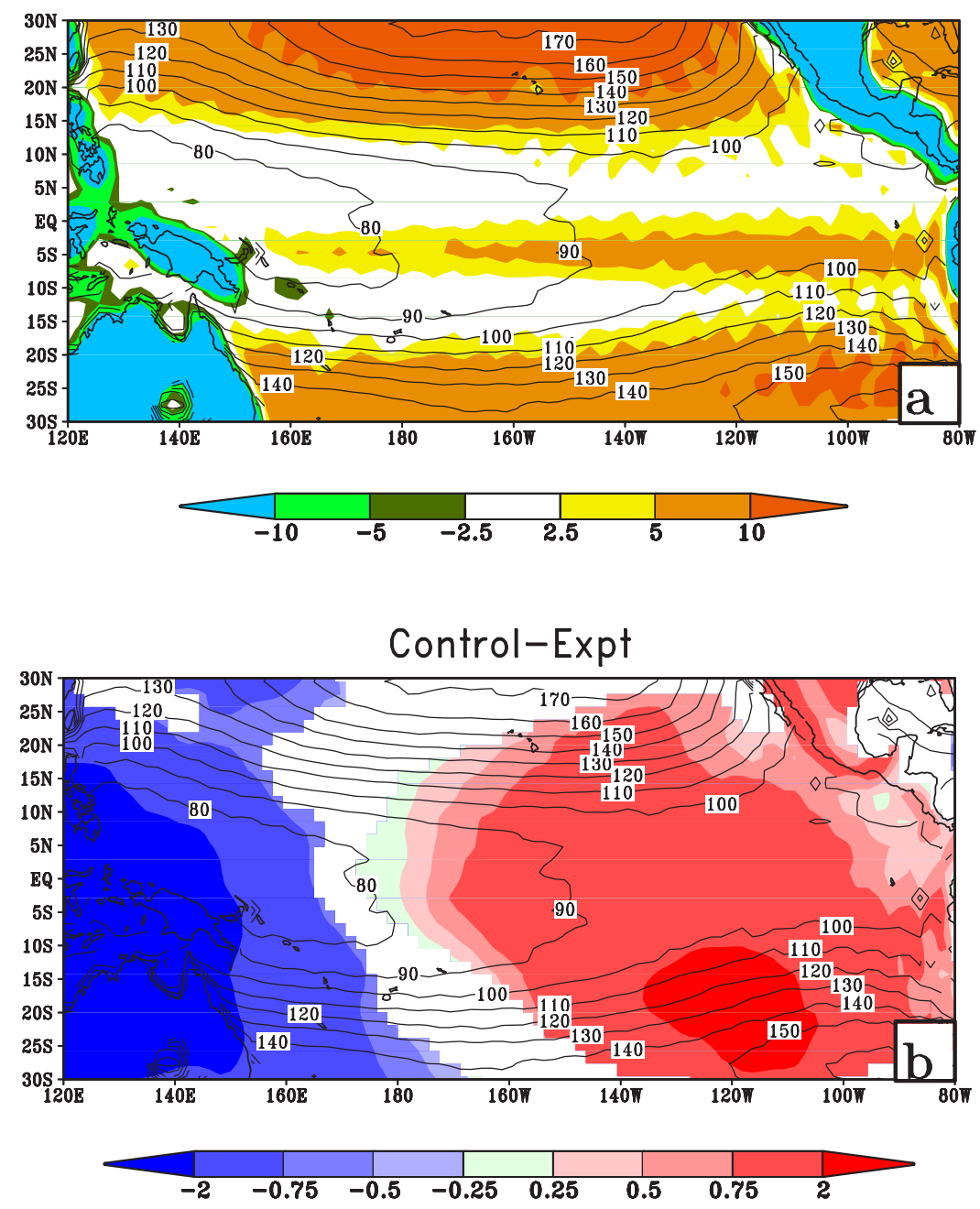

Figure 7. (a) Climatological annual mean of the surface pressure after its zonal mean is removed from the control. (b) Corresponding difference from the Expt. The contours of climatological $1000 \mathrm{hPa}$ heights (in meters) from the control run are also overlaid. Only significant values at $10 \%$ significance level according to t-test are shaded. 

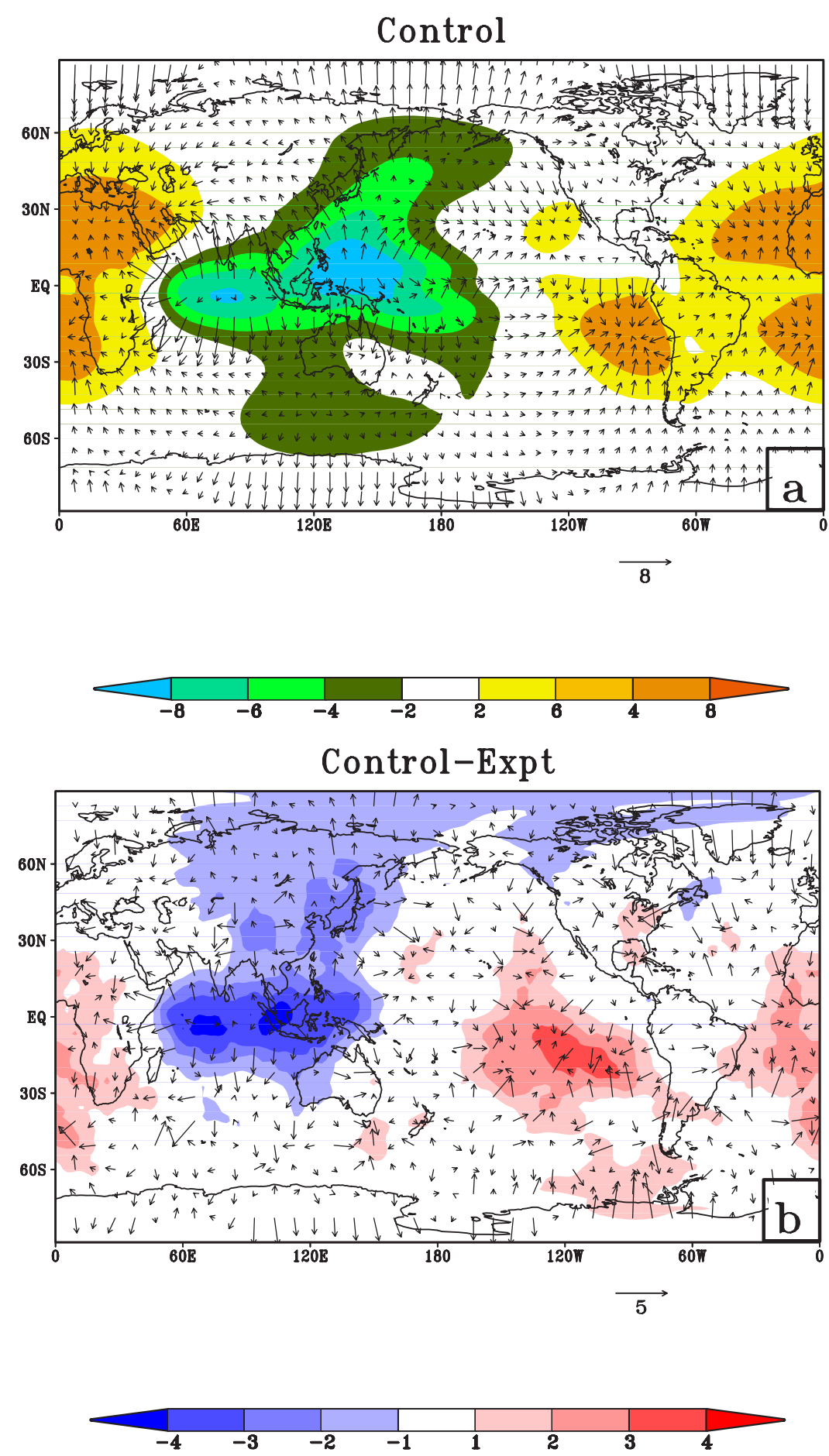

Figure 8. Climatological annual mean of the velocity potential and divergent wind at $200 \mathrm{hPa}$ from (a) control simulation and (b) its difference from the corresponding EXPT simulation (only significant values at $10 \%$ significance level according to t-test are shaded). The velocity potential is shaded and scaled by a factor of $1.0 \times 10^{-6} \mathrm{~m}^{2} \mathrm{~s}^{-1}$. The unit of the wind vectors is $\mathrm{m} \mathrm{s}^{-1}$. 

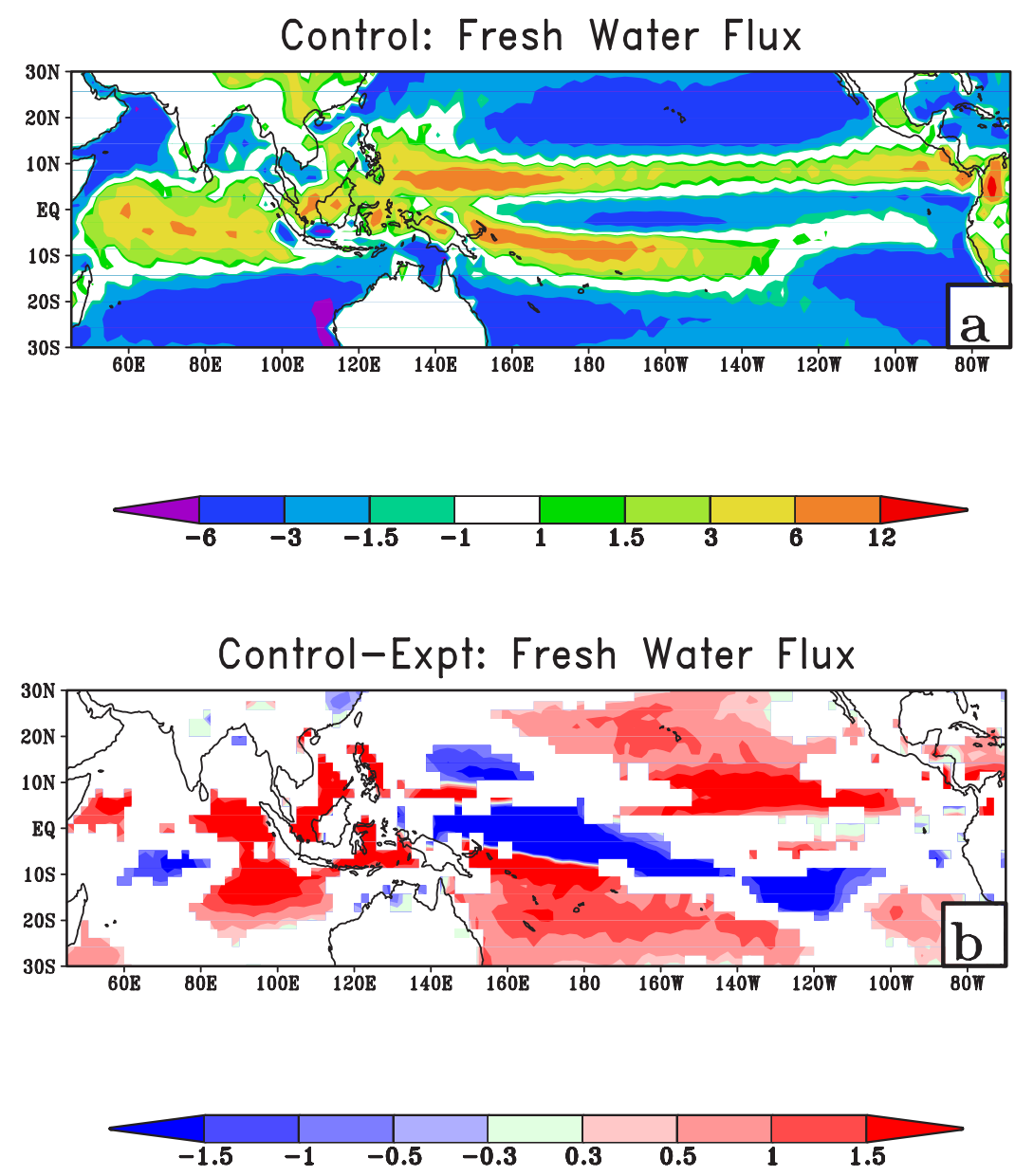

Figure 9. Same as Figure 3 but for fresh water flux. Units are mm day ${ }^{-1}$.

Ocean. This response can only be gauged in a coupled framework where air-sea coupling is incorporated.

\subsection{Interannual Variability}

[24] In Figure 12 we show the scatterplot between the monthly mean thermocline depth and SST anomalies over the Niño3 region. The thermocline depth is diagnosed as the depth of the $20^{\circ} \mathrm{C}$ isotherm. In Figure $12 \mathrm{a}$ the scatterplot is from the ocean data assimilation (ODA) of Rosati et al. [1997] which shows a relatively strong linear relationship between the two variables. This is consistent with the observational analysis of Zelle et al. [2004] who used the Tropical Atmosphere-Ocean/Triangle Trans-Ocean-Buoy Network (TAO/TRITON) array. They attributed this linear relationship between the thermocline depth and SST to strong upwelling. This causes vertical advection of temperature anomalies from the thermocline to the surface and vertical mixing giving rise to the observed lag that range from 2 weeks to 2 months between $90^{\circ} \mathrm{W}$ to $140^{\circ} \mathrm{W}$ over the equator. Since we are using here monthly mean anomalies of the thermocline depth and SST, this relationship appears contemporaneous in the ODA in Figure 12a. In contrast, the Expt in Figure 12b shows a much weaker linear relationship with linear correlation of 0.24 compared to 0.77 from the ODA in Figure 12a. The control simulation displays a much stronger linear relationship (Figure 12c) that compares well with the ODA.
[25] Similarly, the Niño3 SST spectrum shows a weak interannual variation in the Expt relative to either the observations (HADISST) or the control simulation (not shown).

[26] Likewise, the midlatitude atmospheric response to Niño3 SST anomalies also show some important differences between the control and Expt simulations. The regression of the $200 \mathrm{hPa}$ height anomalies on the contemporaneous Niño3 SST anomalies is shown in Figures 13a, 13b and 13c from NCEP reanalysis, control and Expt integrations respectively. The reanalysis in Figure 13a display the typical SST forced pattern over the Pacific North American region [Horel and Wallace, 1981]. The reanalysis also shows a near uniform height anomalies in the tropical latitudes that is pointed as a feature of the ENSO variability [Yulaeva and Wallace, 1994]. The control simulation (Figure 13b) reproduces this variability pattern reasonably well when compared with the NCEP reanalysis. However Expt (Figure 13c) displays a wave like pattern reminiscent of that obtained from internal variability as described by Straus and Shukla [2000, cf. their Figure 10]. Furthermore there is no significant height anomaly over the tropical latitudes in the Expt.

\section{Discussion and Conclusions}

[27] In this study we find that the shallow trade wind inversion clouds have a significant impact on the coupled 

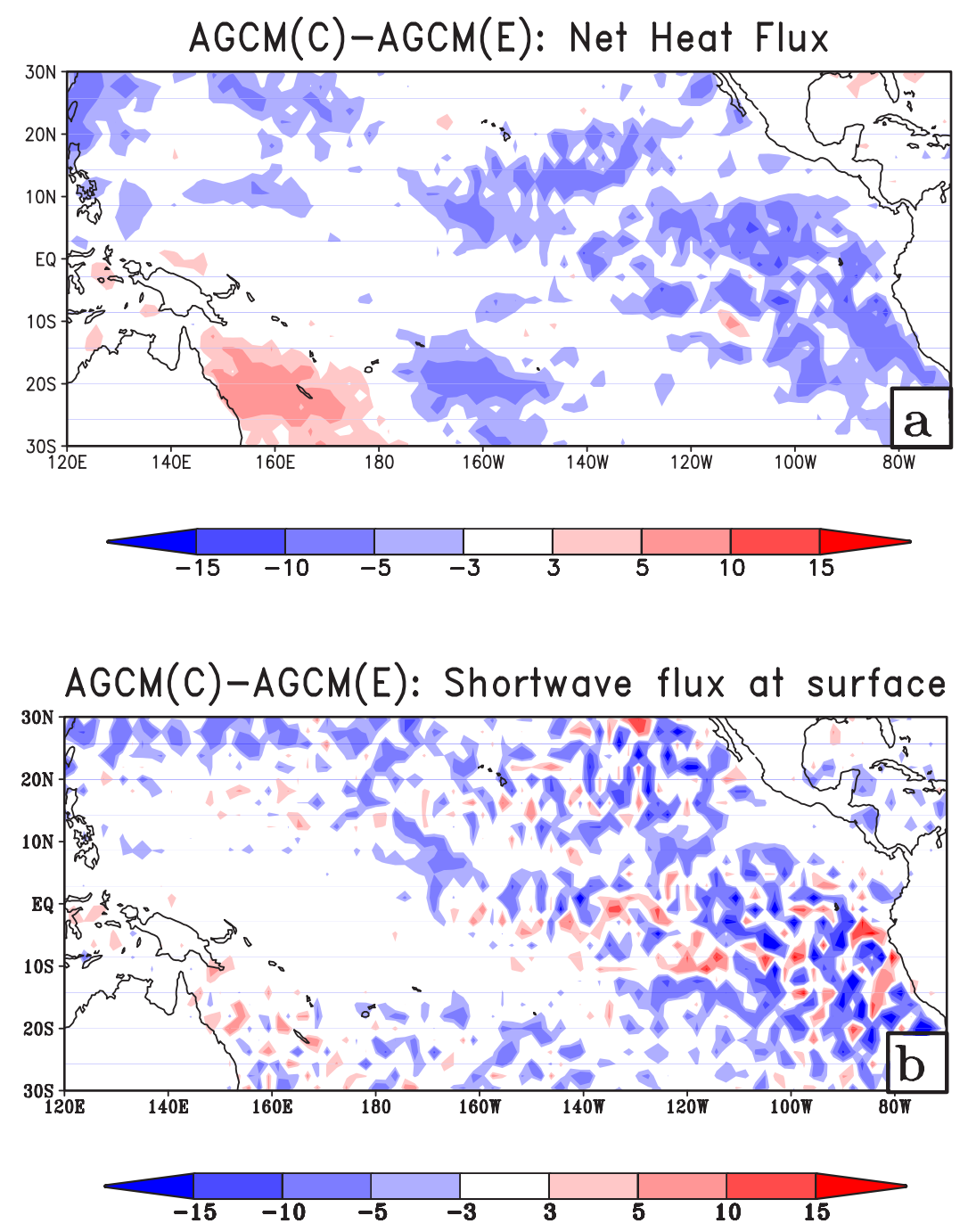

Figure 10. Difference of (a) net heat flux and (b) downwelling shortwave flux at surface between $\mathrm{AGCM}(\mathrm{C})$ and $\mathrm{AGCM}(\mathrm{E})$ experiments. Units are $\mathrm{W} \mathrm{m}^{-2}$.
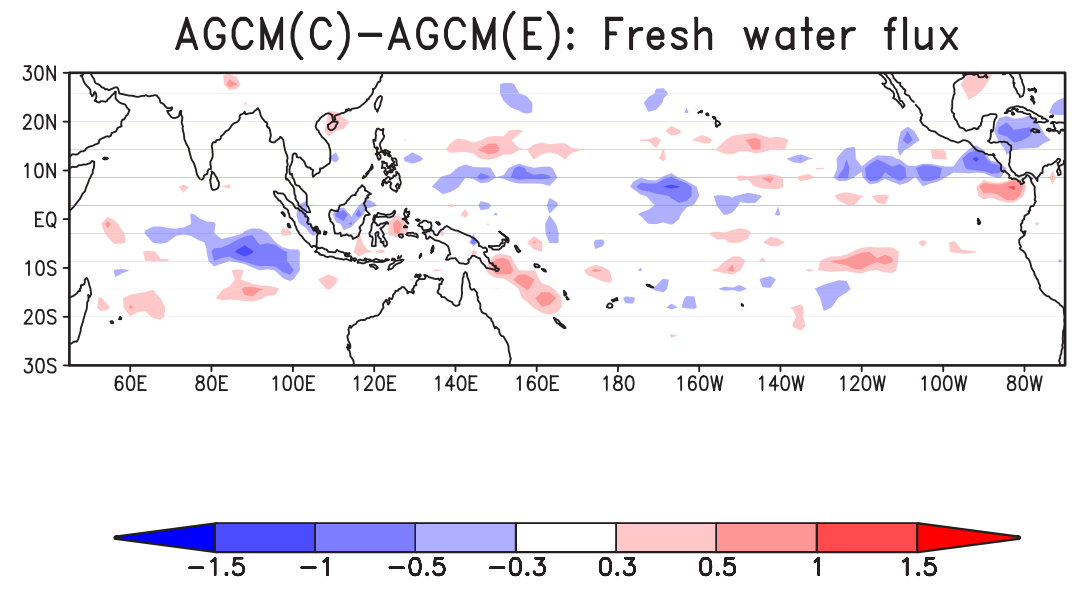

Figure 11. Difference of fresh water flux between $\operatorname{AGCM}(C)$ and $\operatorname{AGCM}(\mathrm{E})$ experiments. Units are $\mathrm{mm}$ day $^{-1}$. 


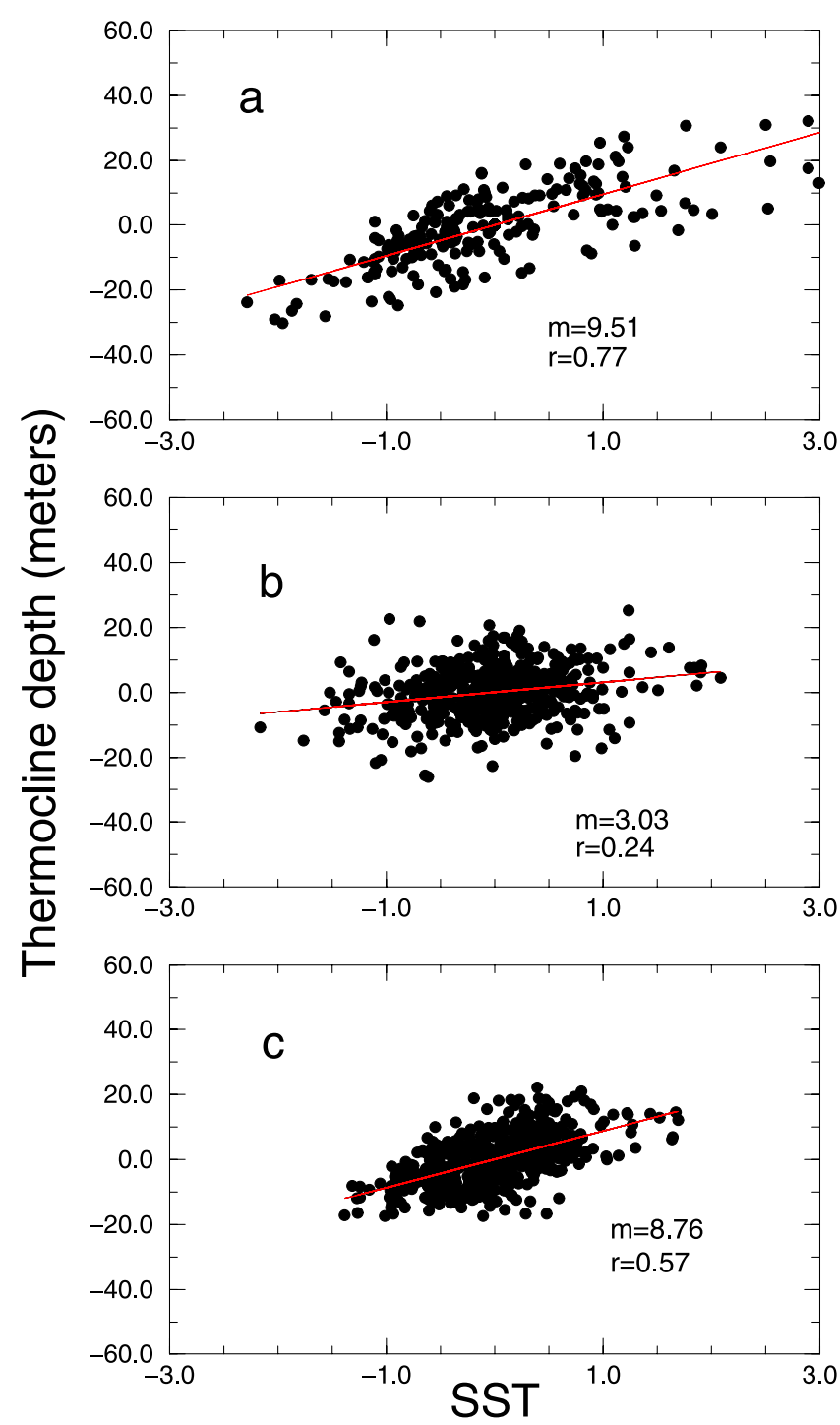

Figure 12. Scatterplot of thermocline depth (in meters) versus SST $\left({ }^{\circ} \mathrm{C}\right)$ over the Niño3 region from (a) ODA [Rosati et al., 1997], (b) Expt and (c) control simulations. The slope (m) and correlation (r) of the linear fit to the scatter are indicated in the legend.

climate of the tropical Pacific Ocean. A rather trivial change in our AGCM to the global distribution of the inversion clouds involving a simple one-dimensional smoother resulted in a "daisy chain" like response of the coupled climate system.

[28] We conducted two long-term coupled simulations using the Center for Ocean-Land-Atmosphere Studies (COLA) coupled climate model. The control simulation used a three-point smoother to reduce the spectral effects on the inversion clouds. The Expt simulation was conducted without smoothing the inversion clouds. Although the inversion clouds were most prevalent in the southeastern (northeastern) flank of the northern (southern) subtropical high and in the equatorial cold tongue region of the eastern Pacific Ocean, the response of the SST and convection in the atmosphere to the modulation of the inversion clouds was most significant in the warm pool region over the western Pacific Ocean.

[29] It is shown from this study that the presence of coherent inversion clouds (as in the control simulation of this study) results in apparent local cooling of the lower troposphere (below $700 \mathrm{hPa}$ ) thereby setting up a surface pressure gradient over the equatorial Pacific that is conducive for stronger low-level easterlies. The absence of coherent (or presence of noisy) inversion clouds as in the Expt model of this study results in weak low-level easterlies compared to the control simulation. The increased zonal cold advection of the SST westward to the warm pool region results in a relative decrease in SST. It should be noted that the thermocline depth in both the coupled simulations are nearly identical in the equatorial western Pacific Ocean (not shown). This indicates that the surface (mixed layer) processes over the equatorial Pacific Ocean are important in determining this sensitivity. This is consistent with the results of Loschnigg and Webster [2000]. In that study, using a one-dimensional mixed layer ocean model they computed and contrasted the heat budget of the upper ocean in the warm pool region of the western Pacific and the eastern Indian Ocean. They found that in the warm pool region of the western Pacific the mean annual cycle of SST is regulated by a combination of local thermodynamic balance and large-scale atmospheric circulations forced by SST gradients. In contrast, they found that over the Indian Ocean cross-equatorial heat transport by oceanic advection is significant in modulating the heat storage of the upper ocean.

[30] The reduction of the SST over the warm pool region in the control results in reduced in situ convective activity over the warm pool region of the western Pacific Ocean thereby, affecting the Walker and Hadley circulations. As a consequence of the stronger easterlies in the control that further fuels downstream convection through increased evaporation, the Walker circulation becomes stronger relative to the Expt. However, the ascending cell of the Walker circulation is shifted westward over the Indian Ocean compared to the Expt. Consequently with the reduced convective activity over the western Pacific Ocean there is a reduction in the total cloud cover and a resulting relative increase in the net heat flux over the warm pool region in the control relative to the Expt.

[31] There are significant differences in the interannual variation over the Niño3 region. The SST in the Expt does not relate to the subsurface anomalies in the Expt as strongly as in the ODA or in the control simulation. Consequently, the interannual variations of the Niño3 SST is much weaker in the Expt. Furthermore the midlatitude height response to the Niño3 SST anomalies in the Expt simulation is reminiscent of the intrinsic variability rather than the forced response. Some of these results are consistent with earlier studies conducted with other climate models using prescribed low level clouds [Gordon et al., 2000]. Similar sensitivity over the equatorial Pacific Ocean was observed when the spatial filter to the inversion clouds in the control was changed from a three point to a five point filter (not shown). However using the five point filter weakened the interannual variation over the equatorial Pacific (not shown) relative to the control but was stronger than the Expt. 

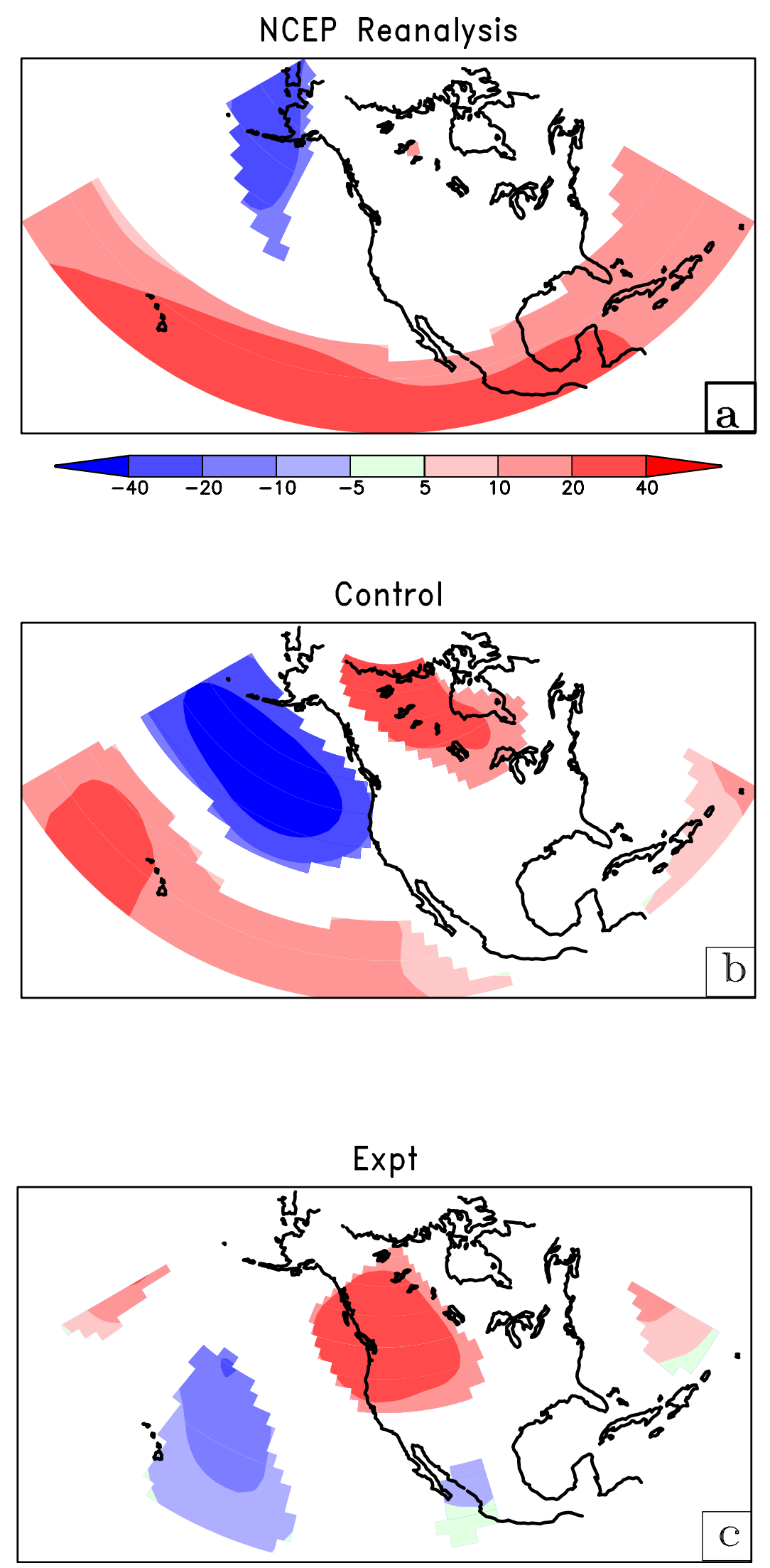

Figure 13. Regression of the DJF Niño3 SST index with contemporaneous geopotential height at $200 \mathrm{hPa}$ from the (a) NCEP reanalysis, (b) control, and (c) Expt coupled simulations. The units are in $\mathrm{m}$. Only significant values at $10 \%$ significance level according to t-test are shaded. 
[32] In many spectral models, the effects from spectral method are shielded by using large horizontal diffusion coefficients, which are largely meant for numerical stability sans any physical reasoning. We have reduced this diffusion coefficient by 2 orders of magnitude from our earlier version of the AGCM [Schneider, 2002] mainly to reduce its role in governing the climate of the model. Furthermore, advection by the spectral method provides an explicit control of the horizontal diffusion. As a result, in this study, the sensitivity of the inversion clouds on the mean climate over the equatorial Pacific Ocean could be isolated. Another commonly adopted approach in GCMs is to smooth the orography [Fennessy et al., 1994] or introduce enhanced orography [Mesinger et al., 1988] that can affect the simulation of the inversion clouds in a GCM through induced spectral effects on the prognostic variables. The choice of advective schemes can also affect the role of the Gibbs effect on the inversion clouds when some schemes are implicitly more diffusive than others.

[33] This study also highlights the importance of developing coupled models in a coupled framework where all components models including that of atmosphere, ocean and land are simultaneously integrated. However, for the coupled simulations in this study, the remote and nontrivial influence of the inversion clouds over the warm pool region could not have been isolated.

[34] Acknowledgments. This study was supported by NSF grant ATM0332910, NASA grant NNG04GG469 and NOAA grant NA04OAR4310034. The authors would also like to acknowledge useful discussions with Ben Kirtman and Ben Cash. The authors thank two anonymous reviewers who gave very helpful suggestions that have considerably improved the quality of this manuscript. The authors acknowledge the support of the computing infrastructure provided by the National Center for Atmospheric Research computing systems laboratory and the computing resources at the NASA, Ames facility under NASA project NNG06GB54G and Columbia project SMD-05-0115.

\section{References}

Bacmeister, J., et al. (2000), An atlas of seasonal means simulated by the NSIPP-1 atmospheric GCm. 17, NASA Tech Memo 104606, 194 pp., NASA Goddard Space Flight Cent., Greenbelt, Md.

Bretherton, C., et al. (2004), The EPIC 2001 stratocumulus study, Bull. Am. Meteorol. Soc., 85, 967-977.

Briegleb, B. P. (1992), Delta-Eddington approximation for solar radiation in the NCAR Community Climate Model, J. Geophys. Res., 97, 7603-7612.

Collins, W. D., J. K. Hackney, and D. P. Edwards (2002), An updated parameterization for infrared emission and absorption by water vapor in the National Center for Atmospheric Research Community Atmosphere Model, J. Geophys. Res., 107(D22), 4664, doi:10.1029/ 2001JD001365.

Dirmeyer, P. A., and F. J. Zeng (1999), Precipitation infiltration in the Simplified SiB land surface scheme, J. Meteorol. Soc. Jpn., 78, 291-303.

Fennessy, M. J., et al. (1994), The simulated Indian monsoon: A GCM sensitivity study, J. Clim., 7, 33-43.

Gordon, C. T., A. Rosati, and R. Gudgel (2000), Tropical sensitivity of a coupled model to specified ISCCP low clouds, J. Clim., 13, 2239-2260.

Hartmann, D. L., M. E. Ockert-Bell, and M. L. Michelsen (1992), The effect of cloud types on Earth's energy balance: Global analysis, J. Clim., $5,1281-1304$.

Hong, S. Y., and H. L. Pan (1996), Nonlocal boundary layer vertical diffusion in a medium range forecast model, Mon. Weather Rev., 124, $2322-$ 2339.

Horel, J. D., and J. M. Wallace (1981), Planetary scale atmospheric phenomena associated with the Southern Oscillation, Mon. Weather Rev. $109,813-829$.

Hu, Z.-Z., B. Huang, and K. Pegion (2007), Low clouds over the southeastern tropical Atlantic Ocean and their climate effects in a coupled GCM and observations, COLA Tech. Rep., 232, 40 pp., Cent. for Ocean-Land-Atmos. Stud., Inst. of Global Environ. and Soc., Calverton, Md. (Available at ftp://grads.iges.org/pub/ctr/ctr_232.pdf)
Kalnay, E., et al. (1996), The NCEP/NCAR 40-year reanalysis project, Bull. Am. Meteorol. Soc., 77, 437-471.

Kiehl, J. T., J. J. Hack, G. Bonan, B. A. Boville, D. L. Williamson, and P. J. Rasch (1998), The National Center for Atmospheric Research Community Climate Model: CCM3, J. Clim., 11, 1131-1149.

Klien, S. A., and D. L. Hartmann (1993), The seasonal cycle of low stratiform clouds, J. Clim., 6, 1587-1606.

Levitus, S. (1982), Climatological Atlas of the World Ocean, NOAA Prof. Pap. 13, 173 pp., U.S. Govt. Print. Off., Washington, D. C.

Loschnigg, J., and P. J. Webster (2000), A coupled ocean-atmosphere system of SST modulation for the Indian Ocean, J. Clim., 13, 33423360 .

Ma, C.-C., C. R. Mechoso, A. Arakawa, and J. D. Farrara (1994), Sensitivity of a coupled ocean-atmosphere model to physical parameterizations, J. Clim., 7, 1883-1896.

Ma, C.-C., C. R. Mechoso, A. W. Robertson, and A. Arakawa (1996), Peruvian stratus clouds and the tropical Pacific circulation: A coupled ocean-atmosphere GCM study, J. Clim., 9, 1635-1645.

McCreary, J. P., and D. L. T. Anderson (1991), An overview of coupled ocean atmosphere models of El Niño and the Southern Oscillation, J. Geophys. Res., 96, 3125-3150.

Mechoso, C. R., et al. (1995), The seasonal cycle over the tropical Pacific in coupled ocean-atmosphere general circulation models, Mon. Weather Rev. 123, 2825-2838

Mesinger, F., Z. I. Janjic, S. Nickovic, D. Garilov, and D. G. Deaven (1988), The step mountain coordinate: Model description and performance for cases of Alpine lee cyclogenesis and for a case of Appalachian redevelopment, Mon. Weather Rev., 116, 1493-1518.

Misra, V., et al. (2007), Validating and Understanding the ENSO simulation in two coupled climate models, Tellus, Ser. A, 59, 292-308.

Neelin, J. D., et al. (1992), Tropical air-sea interaction in general circulation models, Clim. Dyn., 7, 73-104.

Pacanowski, R. C., and S. M. Griffies (1998), MOM3.0 manual, NOAA Geophys. Fluid Dyn. Lab., Princeton, N. J.

Philander, S. G. H., D. Gu, G. Lambert, T. Li, D. Halpern, N.-C. Lau, and R. C. Pacanowski (1996), Why the ITCZ is mostly north of the equator?, J. Clim., 9, 2958-2972.

Randall, D. A., J. A. Coakley Jr., C. W. Fairall, R. A. Kropfli, and D. H. Lenschow (1984), Outlook for research on subtropical marine stratiform clouds, Bull. Am. Meteorol. Soc., 65, 1290-1301.

Rao, K. A., and K. Sperber (2002), Simulation of the El Niño Southern Oscillation: Results from the Coupled Intercomparison Project, Climate Dynamics, 19, 191-209, doi:10.1007/s00382001-0221-9.

Rayner, N. A., D. E. Parker, E. B. Horton, C. K. Folland, L. V. Alexander, D. P. Rowell, E. C. Kent, and A. Kaplan (2003), Global analyses of sea surface temperature, sea ice, and night marine air temperature since the late nineteenth century, J. Geophys. Res., 108(D14), 4407, doi:10.1029/ 2002JD002670.

Rosati, A., R. Gudgel, and K. Miyakoda (1997), The impact of ocean initial conditions on ENSO forecasting with a coupled model, Mon. Weather Rev., 125, 754-772.

Rossow, W. B., and R. A. Schiffer (1999), Advances in understanding clouds from ISCCP, Bull. Am. Meteorol. Soc., 80, 2261-2288.

Schneider, E. K. (2002), Understanding differences between the equatorial Pacific as simulated by two coupled GCMs, J. Clim., 15, 449-469.

Slingo, J. M. (1987), The development and verification of a cloud prediction model for the ECMWF model, Q. J. R. Meteorol. Soc., 113, 899927.

Stevens, B., et al. (2003), Dynamics and Chemistry of Marine Stratocumulus DYCOMS-II, Bull. Am. Meteorol. Soc., 84, 579-593.

Stockdale, T., M. Latif, G. Burgers, and J.-O. Wolff (1994), Some sensitivities of a coupled ocean-atmosphere GCM, Tellus, Ser. A, 46, 367-380. Straus, D., and J. Shukla (2000), Distinguishing between SST-forced variability and internal variability in the mid-latitudes: Analysis of observations and GCM simulation, Q. J. R. Meteorol. Soc., 126, 2323-2350.

Tiedtke, M. (1984), The effect of penetrative cumulus convection on the large-scale flow in a general circulation model, Beitr. Phys. Atmos., 57, $216-239$.

Wang, Y., S.-P. Xie, H. Xu, and B. Wang (2004), Regional model simulations of marine boundary layer clouds over the southeast Pacific off South America. Part I: Control experiment, Mon. Weather Rev., 132, 274-296.

Webster, P. J. (1994), The role of hydrological processes in oceanatmosphere interactions, Rev. Geophys., 32, 427-476.

Webster, P. J., T. Palmer, M. Yanai, V. Magana, J. Shukla, R. A. Tomas, and A. Yasunari (1998), Monsoons: Processes, predictability and the prospects for prediction, J. Geophys. Res., 103(C7), 14,451-14,510.

Xue, Y.-K., P. J. Sellers, J. L. Kinter, and J. Shukla (1991), A simplified biosphere model for global climate studies, J. Clim., 4, 345-364. 
Xue, Y.-K., F. J. Zeng, and C. A. Schlosser (1996), SSiB and its sensitivity to soil properties. A case study using HAPEX-Mobilhy data, Global Planet. Change, 13, 183-194.

Yu, J.-Y., and C. R. Mechoso (1999a), Links between annual variations of Peruvian stratocumulus clouds and of SST in the eastern equatorial Pacific, J. Clim., 12, 3305-3318.

Yu, J.-Y., and C. R. Mechoso (1999b), A discussion on the errors in the surface heat fluxes simulated by a coupled GCM, J. Clim., 12, 416-426.

Yulaeva, E., and J. M. Wallace (1994), The signature of ENSO in global temperature and precipitation fields derived from the microwave sounding unit, J. Clim., 7, 1719-1736.
Yuter, S. E., Y. L. Serra, and R. A. Houze Jr. (2000), The 1997 Pan American Climate Studies Tropical Eastern Pacific Process Study. Part II: Stratocumulus region, Bull. Am. Meteorol. Soc., 81, 483-490.

Zelle, H., G. Appeldoorn, G. Burgers, and G. J. van Oldenborgh (2004), The relationship between sea surface temperature and thermocline depth in the eastern equatorial Pacific, J. Phys. Oceanogr., 34, 643-655.

L. Marx and V. Misra, Center for Ocean-Land-Atmosphere Studies, Institute of Global Environment and Society, Inc., 4041 Powder Mill Road, Suite 302, Calverton, MD 20705, USA. (misra@cola.iges.org) 